(c) American Dairy Science Association, 2006.

\title{
Major Scientific Advances with Dairy Foods in Nutrition and Health
}

\author{
P. J. Huth, ${ }^{1}$ D. B. DiRienzo, and G. D. Miller \\ National Dairy Council, Rosemont, IL 60018-5616
}

\begin{abstract}
A large body of scientific evidence collected in recent decades demonstrates that an adequate intake of calcium and other nutrients from dairy foods reduces the risk of osteoporosis by increasing bone acquisition during growth, slowing age-related bone loss, and reducing osteoporotic fractures. These results have culminated in the new (2005) Dietary Guidelines for Americans that now recommend 3 servings of milk products per day to reduce the risk of low bone mass and contribute important amounts of many nutrients that may have additional health attributes beyond bone health. A number of animal, observational, and clinical studies have shown that dairy food consumption can help reduce the risk of hypertension. Clinical trials indicate that the consumption of recommended levels of dairy products, as part of a healthy diet, can contribute to lower blood pressure in individuals with normal and elevated blood pressure. Emerging data also indicate that specific peptides associated with casein and whey proteins can significantly lower blood pressure. In addition, a growing body of evidence has provided support for a beneficial effect of dairy foods on body weight and fat loss. Clinical studies have demonstrated that during caloric restriction, body weight and body fat loss occurs when adequate calcium is provided by supplements and that this effect is further augmented by an equivalent amount of calcium supplied from dairy foods. Several studies support a role for calcium, vitamin D, and dairy foods against colon cancer. Additionally, conjugated linoleic acid, a fatty acid found naturally in dairy fat, confers a wide range of anticarcinogenic benefits in experimental animal models and is especially consistent for protection against breast cancer.
\end{abstract}

Key words: dairy food, nutrition, health, chronic disease

\section{INTRODUCTION}

Milk has been recognized as a staple of the human diet since the agricultural revolution, approximately

Received April 18, 2005.

Accepted August 17, 2005.

${ }^{1}$ Corresponding author: peterh@rosedmi.com
8000 BC. The nutritional value of milk was recognized in an Islamic medical tome that reads: "Drink milk, for it wipes away heat from the heart, strengthens the back, increases the brain, augments the intelligence, renews vision, and drives away forgetfulness." Although these claims are not supported by modern scientific standards, it underscores the high nutritional quality that societies, over the centuries, have associated with milk consumption.

Modern nutrition is a relatively young science that emerged in the early 20th century. Nutritionists quickly recognized the nutrient density of milk and its value in providing essential nutrients in a balanced diet. Since then, the importance of milk in meeting nutrient needs has been emphasized in virtually all US government nutrition programs and public health dietary guideline statements for the last century. Most recently, the 2005 Dietary Guidelines recommend that the majority of Americans increase their intake of milk and milk products to 3 servings per day. Beyond the role of milk as part of a nutrient dense diet that provides necessary nutrients for normal growth and development, research over the past 30 to $40 \mathrm{yr}$ has shown that milk and milk products can help reduce the risk of chronic disorders including osteoporosis, hypertension, excess body weight and body fat, and colorectal cancer.

The aim of this review is to discuss the role of dairy foods in a healthy diet and to describe the major scientific advances leading to specific health benefits associated with adequate dairy food intake.

\section{NUTRITIONAL VALUE OF MILK}

Cow's milk and other dairy foods are the major source of calcium in the US diet, providing more than $70 \%$ of the calcium available in the food supply. In an analysis of food sources of calcium, milk and milk products provided $83 \%$ of the calcium in the diets of young children, $77 \%$ of the calcium in adolescent females' diets, and between 65 and $72 \%$ of the calcium in adults' diets. Pragmatically, it is difficult to achieve dietary calcium recommendations without consuming dairy products.

The public health benefits of calcium are well recognized. The major concern in the United States is meeting current recommended intakes. Unfortunately, most Americans are not meeting the dietary recommenda- 


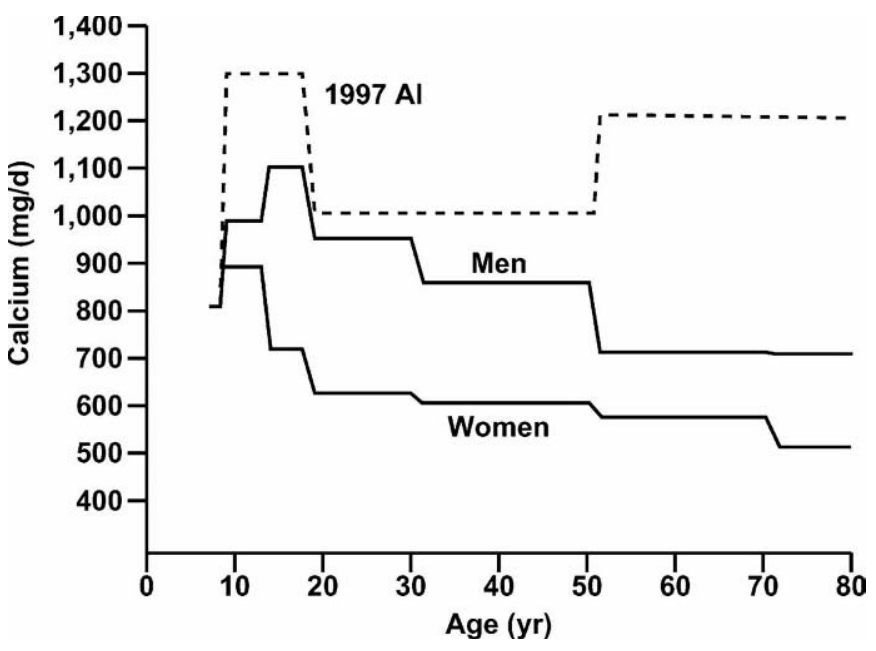

Figure 1. Adequate intakes (AI) for calcium with age (dashed line) compared with mean intakes of calcium for men and women in the United States. Mean intakes for calcium are from the 1994 Continuing Survey of Food Intakes by Individuals, adjusted for day-to-day variation, which do not include calcium intakes from supplements. Adapted from Weaver, 2001; reproduced with permission from International Life Sciences Institute.

tions for calcium, particularly young and adolescent girls and older adults. Surveys by the USDA indicate that 9 out of 10 teenage girls and adult women, and 7 out of 10 teenage boys and adult men fail to meet calcium recommendations. Only 4 to $5 \%$ of women ages 50 and older consume $100 \%$ of the calcium recommendation. Figure 1 shows the gap between the recommended intake for calcium and actual mean intake from the USDA 1994 Continuing Survey of Food Intake by Individuals. Individuals, both male and female, after age 10, do not reach recommended calcium intakes for either males or females. After age 50, the mean intakes by females and males are only about 600 and $700 \mathrm{mg} / \mathrm{d}$, respectively; levels that are only $50 \%$ of the recommended intake. These data indicate that a majority of the US population has inadequate intake of calcium. The low dietary intake of calcium by adolescents is of particular concern because it coincides with a period of rapid skeletal growth, which represents a "window of opportunity" to maximize bone mass. About $90 \%$ of humans' bone mass is achieved by age 17 .

Americans' low calcium intake and the gap between recommended dietary intakes and typical intakes are recognized as a major public health problem. The calcium crisis may be attributed, at least in part, to changes in food consumption patterns of the US population over the past century, in particular the trend toward consuming less milk and more soft drinks. In 1945, Americans consumed more than 4 times as much milk as soft drinks. In contrast, in 1998, 21/3 times more

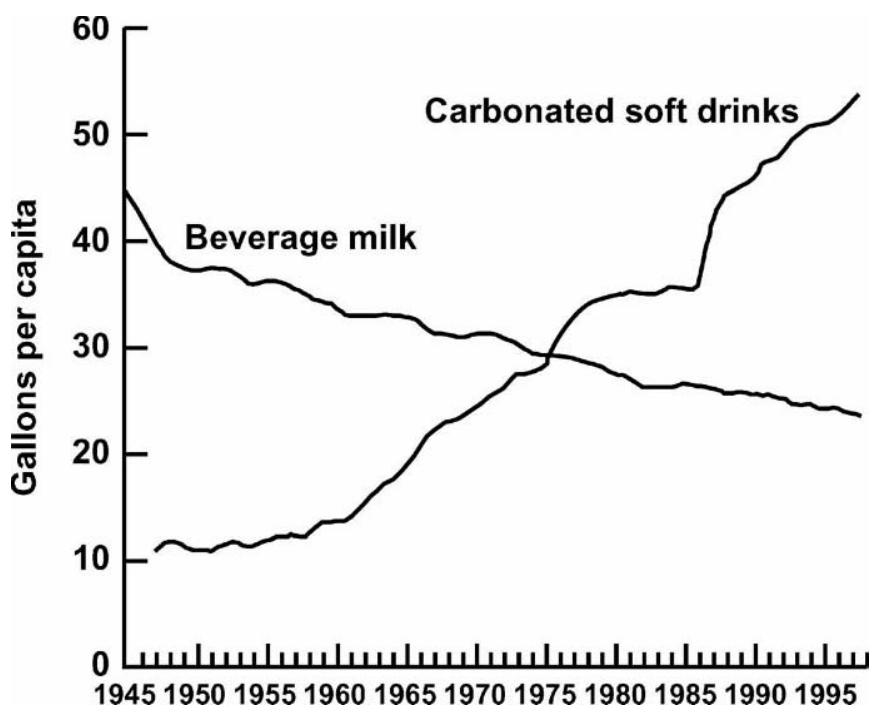

Figure 2. Milk consumption compared with soft drink consumption. Adapted from Putnam (2000).

soda was consumed than milk (Figure 2). After age 8, the intake of soft drinks increases dramatically and by age 18, adolescents drink approximately $19 \mathrm{oz} / \mathrm{d}$, whereas milk consumption decreases to less than $8 \mathrm{oz} /$ d. The USDA's Healthy Eating Index surveys indicate that Americans older than $2 \mathrm{yr}$ of age consumed an average of 1.5 servings/d of dairy foods instead of the 2 to 3 servings/d currently recommended.

A recent National Institutes of Health consensus panel on osteoporosis attributes Americans' low calcium intake to "restriction of dairy products, a generally low level of fruit and vegetable consumption, and a high intake of low calcium beverages such as sodas." In a national survey, only those children consuming milk at lunch met or exceeded calcium recommendations, whereas those consuming soft drinks, juice, or tea did not. A recent study found that high school students who consumed more soft drinks had a higher risk of bone fractures than those consuming fewer soft drinks. These and other data indicate that the low calcium intakes by Americans may be attributed, at least in part, to changes in the food consumption patterns in the United States, in particular the trend toward consuming less milk and more soft drinks.

In the United States, The new MyPyramid food guidance system (www.mypyramid.gov) is the primary science-based nutrition education tool that translates dietary recommendations into simple food guidelines to help consumers meet nutrient needs and prevent chronic disease. The MyPyramid recommends that Americans greater than 8 yr of age consume 3 dairy servings per day. The 2005 Report of the Dietary Guide- 
lines Advisory Committee on the relationships between milk product intake and health concludes: "Consuming three servings of milk and milk products each day can reduce the risk of low bone mass and contribute important amounts of many nutrients. Furthermore, this amount of milk product consumption may have additional benefits and is not associated with increased body weight. Therefore, the intake of three cups of milk products per day is recommended." This is consistent with the work of Fulgoni and coworkers at the National Dairy Council that demonstrated that groups of individuals who met or exceeded the previous (2000) Food Guide Pyramid (FGP) dairy recommendations of 2 to 3 servings/d were more likely to have a mean calcium intake above the recommended intake for calcium, which means the likelihood of inadequate calcium intake in these groups is low. However, the groups that met or exceeded the FGP dairy recommendations had an average dairy intake about 1 serving higher (3 to 4 servings/d) than the 2000 FGP recommendations. Their data indicate that 3 to 4 servings from the milk group for all individuals greater than $9 \mathrm{yr}$ of age is necessary to meet recommendations and to ensure adequate intakes of calcium.

Ensuring adequate calcium intake from foods, such as dairy foods, is crucial as diets inadequate in this nutrient are also low in many other essential nutrients.

It was once believed that some populations (e.g., African-Americans, Asians) might not be able to include dairy foods into their diet because of lactose intolerance. However, it is now known that many individuals diagnosed with lactase nonpersistence (i.e., lactose maldigesters) can tolerate dairy foods quite well by consuming milk with meals, selecting low-lactose dairy foods, or using lactase supplements. This has been reinforced by the National Medical Association in a consensus report on the role of dairy foods in the diets of AfricanAmericans and recommends 3 to 4 servings of dairy foods a day to help achieve recommended calcium intakes as well as other nutrients associated with dairy foods.

Milk and other dairy foods also contribute substantial amounts of other essential nutrients to the US diet (Table 1) including: phosphorus (32\%), riboflavin $(26 \%)$, vitamin $\mathrm{B}_{12}(21 \%)$, protein (19\%), potassium (18.9\%), zinc (16\%), magnesium (16\%), and vitamin A (15\%). Vitamin A is naturally present in whole milk and is added to low-fat and fat-free milk in the United States and Canada; it plays a key role in vision, cellular differentiation, and immunity. Nearly all fluid milks in the United States and Canada are fortified with vitamin D. Fluid milk in the United States is fortified to a standardized level of $400 \mathrm{IU}$ of vitamin D/quart. Fortified milk and ready-to-eat cereals are the predominant food
Table 1. Percentage nutrient contributions of dairy foods (excluding butter) to the US food supply in $1999^{1}$

\begin{tabular}{lc}
\hline Nutrient & Percentage \\
\hline Energy & 9.3 \\
Protein & 19.4 \\
Fat & 12.3 \\
Saturated fat & 24.3 \\
Carbohydrate & 4.6 \\
Minerals & \\
Calcium & 72.1 \\
Phosphorus & 32.4 \\
Zinc & 16.2 \\
Magnesium & 15.8 \\
Iron & 1.8 \\
Potassium & 18.9 \\
Sodium & 31.5 \\
Vitamins & \\
Riboflavin & 26.1 \\
Vitamin $\mathrm{B}_{12}$ & 21.6 \\
Vitamin A & 15.3 \\
Vitamin $\mathrm{B}_{6}$ & 8.7 \\
Folate & 6.2 \\
Thiamin & 4.7 \\
Vitamin E & 2.8 \\
Ascorbic acid & 2.5 \\
Niacin & 1.2 \\
\hline
\end{tabular}

${ }^{1}$ Adapted from Gerrior and Bente (2002).

sources of vitamin D. Some yogurts and processed cheeses also contain added vitamin D. However, milk products such as butter, ice cream, sour cream, cream, cottage cheese, and most varieties of hard and soft cheeses are not generally fortified with vitamin D. Vitamin D's major biologic function in humans is to maintain normal calcium and phosphorus levels in the blood by enhancing the efficiency of their absorption from the diet. Hence, there is a clear interdependence of calcium and vitamin D on the maintenance of skeletal health. Numerous studies have reported that the intake of milk and other dairy foods improve the overall nutrient density and quality of the diet in women, older adults, children, and adolescents. The importance of calcium in reducing the risk of chronic diseases such as osteoporosis was a key factor in setting higher dietary recommendations for this nutrient by the Institute of Medicine in 1997 for children, adolescents, adults (19 to 50 yr) and older adults ( $\geq 51 \mathrm{yr})$ compared with the 1989 recommended daily allowance (Table 2). These higher recommendations coincide with peak calcium accumulation rates in bone that occurs in teenage girls and boys and the age-related decline in calcium absorption among older adults.

\section{HEALTH BENEFITS OF MILK AND MILK PRODUCTS}

The nutritional role of milk as a component of the diet has traditionally been evaluated based on its overall contribution of essential and nonessential nutrients to 
Table 2. National Academy of Sciences (NAS) dietary reference intakes for calcium $(\mathrm{mg} / \mathrm{d})^{1}$

\begin{tabular}{lcc}
\hline & \multicolumn{2}{c}{ Males and Females } \\
\cline { 2 - 3 } Age & NAS $1989^{1}$ & NAS $1997^{2}$ \\
\hline 1 to 3 yr & 500 & 500 \\
4 to 8 yr & 800 & 800 \\
9 to 18 yr & 1,200 & 1,300 \\
19 to 50 yr & 1,200 & 1,000 \\
$>50$ yr & 1,200 & 1,200 \\
\hline
\end{tabular}

${ }^{1}$ Food and Nutrition Board, 1989, 1997.

a high quality diet for the support of optimal growth and development. More recently, however, the consumption of milk and other dairy foods, by virtue of their mineral, bioactive lipids, and protein components, have been shown to help reduce the risk of chronic disease disorders including osteoporosis, hypertension, excess body weight and body fat, dental caries, and some cancers.

\section{OSTEOPOROSIS}

Osteoporosis is generally characterized as the progressive loss of bone mass and deterioration of bone tissue, leading to skeletal weakness and an increased susceptibility to bone fractures. Approximately 10 million US adults aged $50 \mathrm{yr}$ and older suffer from osteoporosis, and another 33 to 34 million have low bone mass and are at high risk for the disease. Bone mass later in life is determined primarily by peak bone mass development, of which more than $90 \%$ is attained by age 20 and $99 \%$ by age 26 . Osteoporosis or low bone mass is recognized today to be a "pediatric disease with geriatric consequences." Although women are 4 times more likely than men to develop osteoporosis, the disease also affects men and occurs in all ages, races, and ethnic groups. Osteoporosis is responsible for approximately 1.5 million spontaneous bone fractures each year, incurring an annual cost of up to $\$ 17$ billion. It is estimated that by 2020, half of Americans over age 50 will have or be at high risk of osteoporosis if preventative measures are not taken. In a 2004 landmark publication, Report on Bone Health and Osteoporosis, the Surgeon General pointed out that it is essential to develop effective strategies throughout life to prevent and manage this bone disease.

\section{The Importance of Peak Bone Mass}

In the past $35 \mathrm{yr}$, observational studies and randomized clinical trials in children, adults, and older adults have demonstrated the importance of peak bone mass development for reducing the risk of osteoporosis and

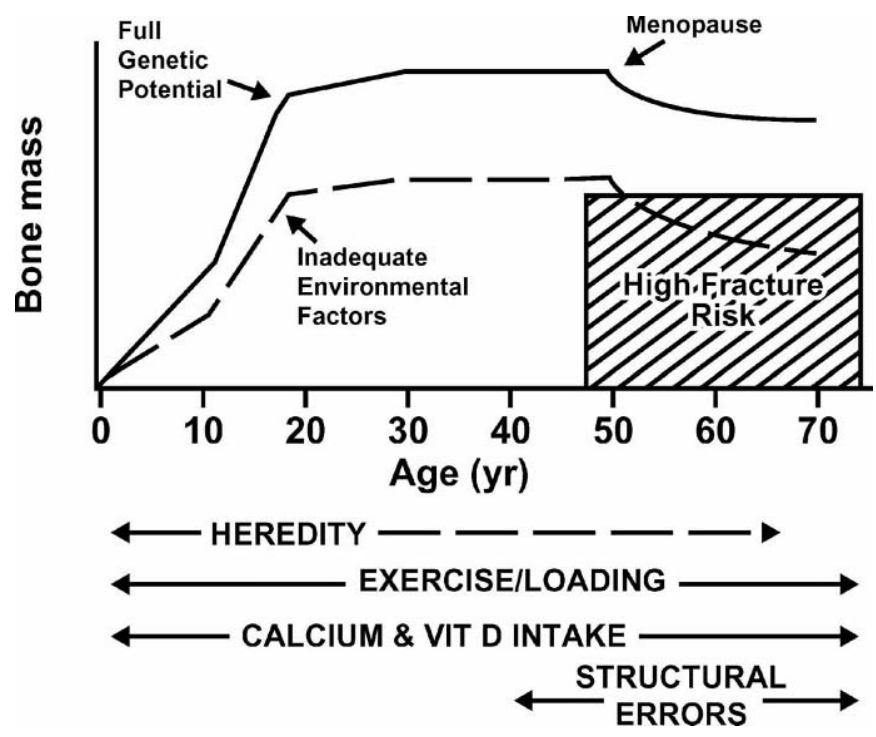

Figure 3. Graphical representation of the bone mass lifeline in individuals who achieve their full genetic potential for skeletal mass and in those who do not. Note: The magnitude of the difference between the curves is not intended to be to scale. Along the bottom of the graph are arrayed several of the factors known to be of particular importance. CRobert P. Heaney, 1999; used with permission.

bone fracture rates later in life. Furthermore, studies have shown that adequate calcium intake from milk and other calcium-rich dairy foods has a significant positive effect on bone mass development.

The bones in the human skeleton grow in length, width, and mass in parallel with overall body growth. In infants, skeletal growth and bone acquisition is initially rapid and then slows somewhat during most of childhood until puberty when it again becomes very rapid. About 85 to $90 \%$ of final adult bone mass is acquired by age 18 in girls and around age 20 in boys. Bone formation and bone resorption (loss) is a dynamic and ongoing process that is in equilibrium under normal conditions in adults. Under conditions of developing osteoporosis from aging and loss of estrogen (menopause), however, the rate of bone resorption exceeds the rate of bone formation resulting in a reduction in bone mass and, hence, in bone strength. The amount and quality of the skeleton achieved by adulthood and, hence, the potential susceptibility to osteoporosis depends on a number of factors including genetic predisposition, nutrient intake, and physical activity. Figure 3 graphically illustrates these factors and the importance of achieving a high peak bone mass by early adulthood for protection against bone fragility and fractures later in life. The importance of achieving peak bone mass in early adulthood for maximal bone strength later in life was first suggested from observational studies showing that older individuals had lower bone mass than 
younger individuals but that the degree of bone loss was proportionately the same in those with high and low starting bone mass. These observations suggested that, in general, bone mass tracks across the life span and that individuals who are at the high end of the population distribution for bone mass development at age 30 will also be at the high end at age 70 . This same pattern of bone mass distribution has also been observed in studies over short time spans in prepubertal children and in older adults. These and other studies have resulted in a consensus that 1) bone mass is an important determinant of bone strength; and 2) achieving a high peak bone mass early in life predicts higher bone mass and greater resistance to fracture later in life.

\section{The Importance of Nutrition and Dairy Products}

Genetic and environmental factors, including nutrition and physical activity, are important factors that influence bone health and risk of osteoporosis. For example, heredity studies of bone mineral density among monozygotic and dyzygotic twins indicate that about $75 \%$ of the variance in peak bone mass is determined by genetic factors that likely involve candidate genes related to growth hormone and insulin-like growth factor pathways, including their receptors and binding proteins.

The role of nutrition in the production and maintenance of bone matrix involves supplying nutrients such as protein, vitamins $\mathrm{C}, \mathrm{D}$, and $\mathrm{K}$, and the minerals copper, manganese, and zinc for the synthesis of collagen and many other proteins. Additionally, calcium, vitamin $\mathrm{D}$, and phosphorus have long been known to be critical for the development of bone. Calcium is the most common mineral in the body and $99 \%$ is stored in the skeleton. The composition of bone is mainly calcium, phosphorus, and protein (about 50\% protein and 50\% calcium phosphate crystals). These components are largely responsible for the structural and mechanical properties of bone. The main food sources of calcium in the US diet and of many of the nutrients involved in bone development are milk and other dairy foods. Dairy foods provide, in addition to high quality protein, both calcium and phosphorus in a ratio that has evolved to be optimal for skeletal growth and development. High calcium intake, especially from dairy foods, along with adequate vitamin $\mathrm{D}$, has been demonstrated to maximize the genetic potential for peak bone mass (which is reached during the first 20 to $30 \mathrm{yr}$ of life), maintain skeletal mass in adulthood, and slow age-related bone loss and reduce the susceptibility to fracture later in life. Support for a causal link between low peak bone mass development and risk of fracture later in life comes from observational studies showing that similar population groups with different lifetime dietary calcium intakes had substantially different bone mass and different hip fracture rates. Furthermore, many studies have shown a positive relationship between bone mineral density in adult women and their milk consumption in childhood and adolescence.

In an analysis of 139 scientific papers published between 1975 and 2000 on the relationship between calcium intake and bone health, 50 of 52 controlled calcium intervention studies showed better bone balance, greater bone gain during growth, reduced bone loss, or decreased fracture risk at high calcium intakes. In a recent assessment of 180 published studies, a positive relationship between calcium intake and bone health was supported in 68 of 70 controlled intervention studies, and all intervention studies that used dairy foods showed a beneficial effect on bone health.

It is becoming increasingly evident that dietary patterns containing naturally nutrient dense foods consisting of milk and other dairy foods positively affect bone health and can reduce the risk of other chronic disease conditions. Researchers have demonstrated, for example, that a dietary pattern such as the Dietary Approaches to Stop Hypertension (DASH) diet-a low fat, calcium, and mineral-rich diet that is high in fruits, vegetables, and dairy products that included approximately 3 servings per day of milk, yogurt, and cheese significantly reduced bone turnover in adults that if sustained may further reduce the risk of osteoporosis. Using these and other studies, researchers conservatively estimated that consuming 3 to 4 servings of dairy foods per day could reduce osteoporosis-related fractures by at least $20 \%$, resulting in healthcare cost savings of more than $\$ 3.5$ billion/yr or $\$ 14$ billion over 5 yr.

Research over the past $35 \mathrm{yr}$ on the relationship between nutritional status and bone health has prompted government and health professional organizations, as well as leading nutritional experts, to recommend food as the preferred source of calcium and other essential nutrients. The National Institute of Child Health and Development has pointed out that "low-fat milk or lowfat milk products are the best sources of calcium because they contain large amounts of calcium along with additional nutrients to help the body better absorb calcium. They also are already a part of the diet of most Americans. Along with calcium, milk provides other essential nutrients, including vitamin $\mathrm{D}$, potassium, and magnesium, all essential for optimal bone health and human development."

The data supporting improved bone health throughout the lifecycle with adequate consumption of calcium and dairy products validate the critical need for regular, lifelong consumption of at least 3 to 4 dairy servings per 
day to maintain the structural integrity of the human skeleton. The 2005 Dietary Guidelines for Americans also recommend 3 cups of milk or the equivalent of milk products per day, preferably nonfat or low-fat products for all persons with energy requirements $\geq 1,600$ calories/d.

\section{HYPERTENSION}

Since the early 1980s, a considerable body of evidence has accumulated from research in animal models, observational studies, and dietary intervention studies that support a beneficial role for the consumption of milk and other dairy foods as well as specific bioactive components of milk in blood pressure control.

\section{Antihypertensive Effects of Calcium and Dairy Foods}

Substantial scientific evidence indicates that calcium and potassium, two nutrients found together in meaningful amounts in dairy foods, have a beneficial effect on blood pressure regulation. The probable importance of the blood pressure lowering effect of calcium in humans was first suggested in a 1984 analysis of the first National Health and Nutrition Examination Survey (NHANES I). Dietary data of more than 10,000 American adults identified an inverse association between dietary calcium and blood pressure levels whereby dietary calcium intakes of $1,000 \mathrm{mg} / \mathrm{d}$ or more were associated with a 40 to $50 \%$ reduction in hypertension prevalence. Of the 17 nutrients assessed in that study, including sodium and potassium, calcium was the only nutrient that differed significantly in intake between persons with and without hypertension. The relationship between higher calcium intake and lower blood pressure has now been reported in numerous population surveys (reviewed by Birkett from the University of Ottawa).

Randomized clinical trials that have assessed the effects of calcium or dairy products on blood pressure have confirmed a blood pressure-lowering effect of adequate calcium consumption from foods and supplements. Although blood pressure responses to modifications in nutrient intake typically vary among individuals, the beneficial blood pressure effect tends to be more consistent when foods rather than calcium supplements are used as the mineral source. This finding indicates that calcium may serve as a marker for dairy foods, and that observed blood pressure benefits are not derived solely from calcium, but from the full nutritional profile of dairy foods, which include multiple minerals, including potassium and magnesium, vitamins, protein and essential fatty acids.
In the landmark DASH controlled-feeding study, persons with high-normal blood pressures consumed 1 of 3 diets for 8 wk. A control, or "typical American," diet was compared with 2 diets lower in total and saturated fat and high in fiber, one that was rich in fruits and vegetables ( 8 to 10 servings/d), and the other rich in fruits and vegetables and also containing 3 servings of dairy products/d. The latter diet (the DASH diet) resulted in impressive reductions in both systolic blood pressure (SBP; $5.5 \mathrm{mmHg}$ ) and diastolic blood pressure (DBP; $3 \mathrm{mmHg}$ ) compared with the typical American diet. The fruits-and-vegetables diet (without the dairy component) produced blood pressure reductions of roughly half that magnitude (SBP: $2.7 \mathrm{mmHg}$; DBP: $1.9 \mathrm{mmHg}$ ).

Subgroup analysis revealed even more profound effects of the DASH diet within certain populations. Among African-Americans, the DASH diet resulted in blood pressure reductions of $6.9 \mathrm{mmHg}$ (SBP) and 3.7 $\mathrm{mmHg}$ (DBP) compared with the control diet. These reductions were approximately double those achieved with the fruits-and-vegetables diet without dairy foods. Particularly noteworthy in this cohort, in which lactose maldigestion is presumed to occur more commonly than in other racial groups, was the lack of adverse gastrointestinal effects with the addition of 3 dairy servings to the daily diet.

Blood pressure changes with the DASH diet were most dramatic in persons with established hypertension ( $\mathrm{SBP} \geq 140$ or $\mathrm{DBP} \geq 90 \mathrm{mmHg}$ ). Although the fruitsand-vegetables diet compared with the control produced decreases of 7.2 and $2.8 \mathrm{mmHg}$ (SBP and $\mathrm{DBP}$ respectively), the DASH diet, with its inclusion of dairy foods, resulted in decreases of 11.4 and $5.5 \mathrm{mmHg}$ (SBP and DBP, respectively). As noted by the investigators, these blood pressure improvements approached those attainable with antihypertensive medications. At study completion, $70 \%$ of the DASH diet group had normal blood pressure (SBP $<140, \mathrm{DBP}<90 \mathrm{mmHg}$ ), compared with $23 \%$ of the control group and $45 \%$ of the fruitsand-vegetables-only diet group.

The effects on blood pressure of the DASH diet were further examined in a second major study-the DASHSodium trial, in which the diet was tested with various levels of sodium. Like the first DASH trial, blood pressure was significantly reduced in persons consuming the DASH diet compared with the control diet, and this occurred across all levels of sodium intake. This study confirmed that for most adults, with the exception of older persons with established hypertension, regular consumption of a high quality diet, rich in fruits, vegetables, and dairy products, is a highly effective dietary means of controlling blood pressure. 
A third major DASH-related study-the PREMIER trial, in which the DASH diet was tested in conjunction with simultaneous lifestyle modifications to improve blood pressure-demonstrated the feasibility of increasing dairy intake in the population. Nearly $60 \%$ of the study participants on the DASH diet met their dairy intake goal, whereas only one-third achieved the fruits and vegetable intake.

A recent multicenter, prospective observational study-the Coronary Artery Risk Development in Young Adults (CARDIA) trial-evaluated the effect of dairy food consumption on risk factors related to the insulin resistance syndrome. A consistent reduction in the incidence $(P<0.001)$ of hypertension was observed with higher consumption of dairy foods, including low and full-fat varieties, butter, and ice cream in overweight individuals $\left(\geq 25 \mathrm{~kg} / \mathrm{m}^{2}\right)$. Other risk factors associated with insulin resistance syndrome were lower with higher dairy intake, including obesity, abnormal glucose tolerance, and dyslipidemia. The 10-yr cumulative incidence of hypertension in those with the lowest dairy consumption $(<10$ servings/wk or $<1.5$ servings/ d) was $22.9 \%$ compared with $8.7 \%$ in those with the highest ( $\geq 35$ servings/wk or $\geq 5$ servings/d) consumption. The odds of elevated blood pressure were considerably lower with the consumption of both low-fat dairy (odds ratio: 0.79 ; 95\% confidence interval: 0.64-0.98) and full-fat dairy (odds ratio: $0.84 ; 95 \%$ confidence interval: $0.71-0.99)$. The odds of elevated blood pressure were lower by nearly $20 \%$ for each daily eating occasion of dairy products.

Taken together, the data set on the antihypertensive effects of 3 servings per day of traditional dairy products in conjunction with a diet high in fruits and vegetables similar to the DASH diet provides persuasive evidence for a beneficial role of dairy products in the prevention of hypertension.

\section{Antihypertensive Peptides from Milk Proteins}

It is well recognized that apart from their basic nutritional role as sources of essential amino acids, many food proteins contain, encrypted within their primary structure, peptide sequences capable of modulating specific physiological functions. Milk proteins, both caseins and whey proteins, are rich sources of bioactive peptides that have been shown to inhibit the activity of angiotensin-I-converting enzyme (ACE), a key regulatory enzyme of the renin-angiotensin system that is a primary modulator of blood pressure as well as fluid and electrolyte balance in the body. Angiotensin-I-converting enzyme converts the inactive angiotensin I hormone into angiotensin II, which constricts vascular smooth muscle, thereby increasing blood pressure. Inhibition of
Table 3. Bovine casein-derived peptides displaying hypotensive effects in spontaneously hypertensive rats ${ }^{1}$

\begin{tabular}{|c|c|c|}
\hline Peptide & $\begin{array}{l}\text { Amino acid } \\
\text { sequence }\end{array}$ & $\begin{array}{l}\text { Maximum } \\
\text { decrease } \\
\text { in } \mathrm{SBP},{ }^{2} \\
\mathrm{mmHg}\end{array}$ \\
\hline \multicolumn{3}{|l|}{$\alpha_{\mathrm{S} 1}$-Casein } \\
\hline$f(1-9)$ & RPKHPIKH & 9.3 \\
\hline$f(23-24)$ & FFVAPFPEVFGK & 34.0 \\
\hline$f(104-109)$ & YKVPQL & 13.0 \\
\hline$f(146-147)$ & YP & 32.1 \\
\hline$f(194-199)$ & TTMPLW & 14.0 \\
\hline \multicolumn{3}{|l|}{$\alpha_{\mathrm{S} 2}$-Casein } \\
\hline$f(189-192)$ & AMPKPW & 5.0 \\
\hline$f(190-197)$ & MKPWIQPK & 3.0 \\
\hline$f(198-202)$ & TKVIP & 9.0 \\
\hline \multicolumn{3}{|l|}{$\beta$-Casein } \\
\hline$f(59-61)$ & VYP & 21.0 \\
\hline$f(59-64)$ & VYPFPG & 22.0 \\
\hline$f(60-68)$ & YPFPGPIPN & 7.0 \\
\hline$f(74-76)$ & IPP & 28.3 \\
\hline$f(80-90)$ & TPVVVPPFLQP & 8.0 \\
\hline$f(84-86)$ & VPP & 32.1 \\
\hline$f(140-143)$ & LQSW & 2.0 \\
\hline$f(169-174)$ & KVLPVP & 32.2 \\
\hline$f(169-175)$ & KLVPVPQ & 31.5 \\
\hline$f(177-183)$ & AVPYPQR & 10.0 \\
\hline
\end{tabular}

${ }^{1}$ Adapted from Fitzgerald et al., 2004; used with permission from the American Society for Nutrition.

${ }^{2} \mathrm{SBP}=$ Systolic blood pressure (mean value).

ACE results in lowering blood pressure and, hence, is a key clinical target for blood pressure control.

It is well established that treatment of milk proteins with the gastrointestinal proteases, pepsin, trypsin, and chymotrypsin, or with bacterial and plant proteases results in the release of ACE inhibitory peptides (ACE-IP) from casein proteins (casokinins) and whey proteins (lactokinins). Therefore, hydrolysates of whole milk protein, caseinates, and whey proteins are good sources of casokinin and lactokinin ACE-IP. Although the structure activity relationship for dairy proteinderived ACE-IP has not been entirely established, it appears that ACE inhibition is strongly influenced by the C-terminal tripeptide amino acid sequence and its positively charged side-chain groups. Many of the potent milk protein-derived ACE-IP contain proline at the C-terminus. For example, the potent casokinins found in skim milk fermented with Lactobacillus helveticus CP790 and Saccharomyces cerevisiae contain the C-terminal amino acid sequences IPP and VPP.

Animal Studies. Numerous studies conducted in spontaneously hypertensive rat models with various casokinins and lactokinins have reported SBP reductions ranging from 2 to $34 \mathrm{mmHg}$ (Tables 3 and 4 ). These studies also indicate that the bioactive oligopeptides of casokinins and lactokinins are able to survive gastrointestinal degradation and can pass from the intestine to the serum to interact with target $\mathrm{ACE}$ recep- 
Table 4. Bovine whey protein-derived peptides displaying hypotensive effects in hypertensive rats $^{1}$

\begin{tabular}{lll}
\hline & $\begin{array}{l}\text { Amino acid } \\
\text { sequence }\end{array}$ & $\begin{array}{l}\text { Maximum } \\
\text { decrease in } \\
\text { SBP, }{ }^{2} \text { mmHg }\end{array}$ \\
\hline$\alpha$-Lactalbumin, f(50-53) & YGLF & 23 \\
$\beta$-Lactoglobulin, f(78-80) & IPA & 31 \\
Bovine serum albumin, f(221-222) & FP & 27 \\
$\beta_{2}$-Microglobulin, f(18-20) & GKP & 26 \\
\hline
\end{tabular}

${ }^{1}$ Adapted from Fitzgerald et al., 2004; used with permission from the American Society for Nutrition.

${ }^{2}$ Systolic blood pressure (mean value).

tors of vascular smooth muscle. The maximum reduction in SBP in these studies with casein-derived ACEIP was $34 \mathrm{mmHg}$ for $\alpha_{\mathrm{S}_{1}}$-casein $\mathrm{f}$ (23-34), and the tripeptides IPP and VPP were reported to reduce SBP in spontaneously hypertensive rats by 28 and $32 \mathrm{mmHg}$ (Table 3). The highest reduction in SBP with wheyderived lactokinins was $31 \mathrm{mmHg}$ reported with $\beta$-lactoglobulin $\mathrm{f}(78-80)$. The potent reductions in SBP observed with many whey-derived lactokinins have been observed with peptide fragments containing 4 or fewer amino acid residues (Table 4).

Human Studies. A growing number of human studies have shown significant reductions in blood pressure with fermented milks and milk-derived peptides from both casein and whey (Table 5). The blood pressurelowering effect in humans was first described in a 1992 report in hypertensive subjects who consumed $20 \mathrm{~g} / \mathrm{d}$ of a tryptic hydrolysate of casein for 4 wk resulting in significant SBP and DBP reductions of -6.6 and -4.6 $\mathrm{mmHg}$. Other well-controlled studies with fermented milks in which mildly hypertensive subjects consumed 95 to $150 \mathrm{~mL} / \mathrm{d}$ of fermented milks containing the potent VPP and IPP casokinins for 8 or $21 \mathrm{wk}$ resulted in SBP reductions ranging from -6.7 to $-14.9 \mathrm{mmHg}$ and $\mathrm{DBP}$ reductions ranging from -3.6 to $-6.9 \mathrm{mmHg}$.

Emerging evidence suggests that consumption of whey protein hydrolysates may result in significant re- ductions in blood pressure. In a recent preliminary report of borderline hypertensive subjects who consumed $20 \mathrm{~g} / \mathrm{d}$ of a whey protein isolate hydrolysate for $6 \mathrm{wk}$, significant reductions in SBP and DBP of -11 and -7 $\mathrm{mmHg}$, respectively, were observed compared with a nonhydrolyzed whey protein isolate control.

The blood pressure-lowering effects of specific hydrolysates of whey and casein proteins or fermented dairy products provide compelling evidence for a beneficial role of dairy peptides to induce clinically significant reductions in SBP and DBP with no reported adverse effects. Commercial products in the form of fermented milks and protein hydrolysates are currently in the marketplace or under development that are aimed at exploiting the antihypertensive benefits of milk-derived bioactive peptides. Additional peer-reviewed studies are needed to provide unequivocal evidence for the independent blood pressure-lowering effects of milk proteinderived bioactive peptides.

\section{WEIGHT CONTROL AND BODY FAT}

Starting in the early 1980 s, an emerging body of scientific evidence has accumulated from epidemiological, animal model, and clinical studies suggesting that dietary calcium and other potential components provided from dairy products may contribute to alterations in metabolic partitioning of dietary energy, resulting in enhanced reductions in body weight and body fat.

\section{Human Studies}

Epidemiologic Studies. To date, numerous observational studies have identified a strong inverse relationship between body weight and dietary calcium and dairy product intake. One of the earliest indications that dietary calcium and dairy products might affect body weight was a 1984 analysis of the NHANES I database that reported a statistically significant inverse association between calcium intake and body

Table 5. Hypotensive effects of fermented milks and milk peptides in humans ${ }^{1}$

\begin{tabular}{|c|c|c|c|c|c|}
\hline Sample & $\begin{array}{l}\text { Peptide } \\
\text { sequence }\end{array}$ & Dose & $\begin{array}{l}\text { Duration, } \\
\text { wk }\end{array}$ & $\begin{array}{l}\text { Maximum } \\
\text { decrease } \\
\text { in DBP }{ }^{2} \\
\mathrm{mmHg}\end{array}$ & $\begin{array}{l}\text { Maximum } \\
\text { decrease } \\
\text { in SBP, } \\
\mathrm{mmHg}\end{array}$ \\
\hline Tryptic casein & - & $20 \mathrm{~g} / \mathrm{d}$ & 4 & 4.6 & 6.6 \\
\hline Calpis & VPP/IPP & $95 \mathrm{~mL} / \mathrm{d}$ & 8 & 6.9 & 14.1 \\
\hline Fermented milk & VPP/IPP & $150 \mathrm{~mL} / \mathrm{d}$ & 8 & 8.8 & 14.9 \\
\hline Fermented milk & VPP/IPP & $150 \mathrm{~mL} / \mathrm{d}$ & 21 & 3.6 & 6.7 \\
\hline $\mathrm{C} 12$ & FFVAPFEVFGK & $>0.2 \mathrm{~g} / \mathrm{kg}$ & 4 & 6.5 & 4.5 \\
\hline BioZate & Whey peptides & $20 \mathrm{~g} / \mathrm{d}$ & 6 & 7 & 11 \\
\hline
\end{tabular}

${ }^{1}$ Adapted from Fitzgerald et al., 2004; used with permission from the American Society for Nutrition.

${ }^{2} \mathrm{DBP}=$ Diastolic blood pressure; SBP = systolic blood pressure. 
weight. In a later trial examining the antihypertensive effect of calcium in obese African-Americans, researchers observed that increasing calcium intake from approximately 400 to $1,000 \mathrm{mg} / \mathrm{d}$ by feeding 2 cups of yogurt/d for $1 \mathrm{yr}$ surprisingly reduced body fat by nearly 11 pounds $(4.9 \mathrm{~kg})$ without an accompanying reduction in caloric intake. Subsequently, other studies in African-Americans also showed that high calcium/dairy food intakes have a beneficial effect on body weight and body fat.

More recently, a prospective study (CARDIA, 2002) that tracked more than 3,000 adults aged 18 to $30 \mathrm{yr}$ for $10 \mathrm{yr}$ showed that the risk of weight gain was $67 \%$ lower in those who consumed the most dairy foods compared with those who consumed the least.

Studies in children and adolescents have shown an inverse association between calcium/dairy foods and body fat. In a 3-yr longitudinal study of 53 preschoolers, children with higher calcium/dairy food intake had lower body fat at $5.8 \mathrm{yr}$ than children with lower calcium/dairy food intakes. In a follow-up study, these researchers also showed that in 8-yr-old children, habitual higher intakes of calcium, most of which came from dairy, were associated with lower body fat.

Nearly all of the epidemiological studies in which the primary end point was body composition have shown a beneficial association between calcium, and particularly dairy foods, and lower body weight and body fat.

Clinical Studies. In the first clinical trial directly investigating the effects of calcium and dairy foods on body weight and body fat loss, Zemel and coworkers at the University of Tennessee evaluated 32 obese adult men and women who were instructed to consume a nutritionally balanced weight loss diet reduced in calories by $500 \mathrm{kcal} / \mathrm{d}$ for $24 \mathrm{wk}$ and randomized to a control "low-calcium/dairy" diet (400 to $500 \mathrm{mg}$ of calcium; 0 to 1 serving of dairy foods/d), a "high-calcium" diet (1,200 to $1,300 \mathrm{mg}$ of calcium; control diet supplemented with $800 \mathrm{mg}$ of calcium/d), or a "high-dairy" food diet (1,200 to $1,300 \mathrm{mg}$ of calcium; control diet with 3 to 4 servings of dairy foods/d). As expected, all participants lost body weight and body fat due to the daily caloric restriction of $500 \mathrm{kcal} / \mathrm{d}$. Subjects on the low-calcium control diet lost $6.4 \%$ of their body weight $(-6.6 \mathrm{~kg})$, which was enhanced to $8.6 \%(-8.6 \mathrm{~kg})$ in subjects consuming a high-calcium diet from calcium supplements and $11 \%(-11 \mathrm{~kg})$ in those consuming the high-dairy food diet (Figure 4). A similar trend was observed for body fat loss, with the greatest loss occurring in subjects on the high dairy food diet (Figure 4).

An unexpected finding was a marked change in the distribution of body fat loss. Subjects on the low-calcium diet lost $5.3 \%(-1.4 \mathrm{~kg})$ of their trunk fat. This was increased to $12.9 \%(-2.9 \mathrm{~kg})$ on the high-calcium diet

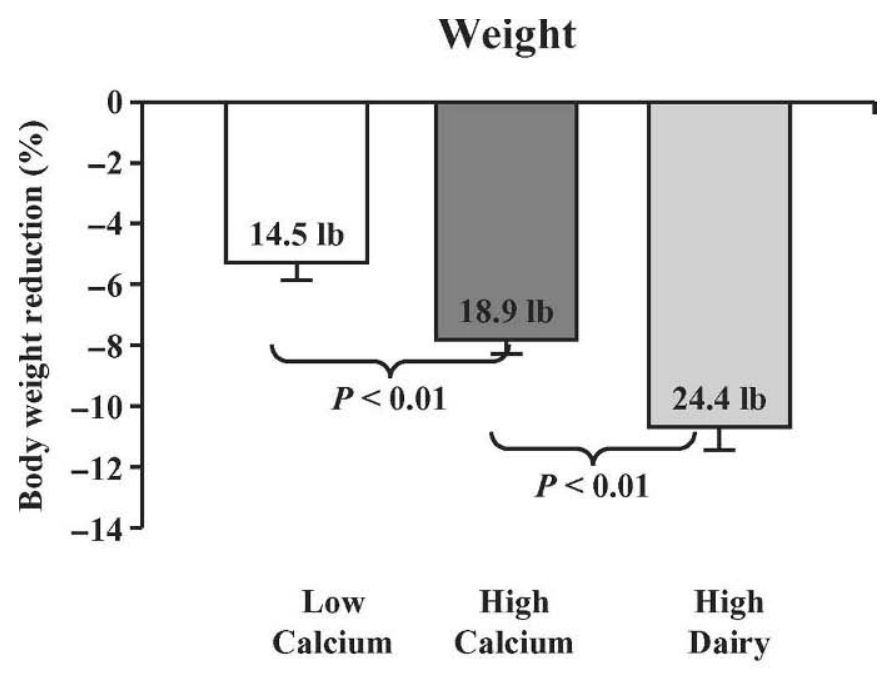

\section{Body Fat}

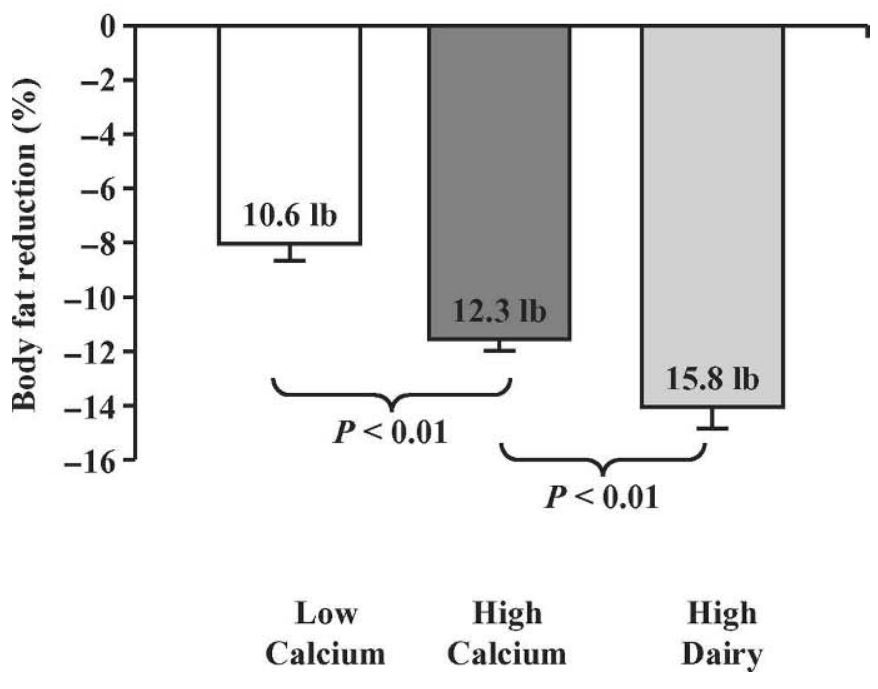

Figure 4. Effects of reduced calorie dietary treatments $(-500 \mathrm{kcal} /$ d) on body weight (top panel) and body fat (bottom panel). Changes in body fat are expressed as a percentage of original body fat. Body weight and fat loss on each diet is significantly different from that on the other 2 diets. Adapted from Zemel et al., 2004; reproduced with permission from NAASO, The Obesity Society.

and $14 \%(-3.7 \mathrm{~kg})$ on the high-dairy diet. These findings have important implications because abdominal obesity is a primary risk factor for metabolic syndrome, a rapidly emerging clinical condition characterized by central obesity, high plasma triglycerides, high blood pressure, low high density lipoprotein-cholesterol, high fasting blood glucose and insulin resistance, and a precursor to type II diabetes. These data also suggest that increasing dietary calcium not only augments weight and fat loss secondary to caloric restriction, but 
also has a more favorable effect on the distribution of fat loss. Additionally, intake of dairy products had a substantially greater effect on both fat loss and fat distribution compared with an equivalent amount of calcium from calcium supplements. In a follow-up study by Zemel and colleagues, 27 obese subjects consuming a similar calorie-restricted weight-loss diet high in calcium $(1,100 \mathrm{mg} / \mathrm{d})$ provided by 3 servings of yogurt for 12 wk lost significantly more body weight, body fat, and abdominal fat than subjects consuming an identical diet low in calcium (400 to $500 \mathrm{mg}$ of calcium/d) and dairy foods (0 to 1 serving/d). This study also observed significantly less loss of lean body mass in subjects on the higher calcium diet vs. the control diet. Furthermore, participants consuming the higher calcium diet exhibited a significant increase in plasma glycerol (a surrogate measure of lipolysis, i.e., fat breakdown), suggesting an increase in body fat lipolysis, whereas no significant change in plasma glycerol was observed in those on the low calcium control diet. In 2 additional studies, Zemel and colleagues evaluated the effects of dairy consumption on body fat and body composition under weight maintenance and weight loss conditions. In the first trial, 34 obese African-American adults were maintained on a low calcium $(500 \mathrm{mg} / \mathrm{d})$; low dairy $(<1$ serving/d) or high calcium (1,200 mg of calcium/d); high dairy ( 3 servings/d) with no change in energy or macronutrient intake for $24 \mathrm{wk}$. No significant changes in body weight were observed between the low and high dairy groups. However, there was a significant reduction in total body fat $(-2.1 \mathrm{~kg})$, trunk fat $(-1.0 \mathrm{~kg})$, and waist circumference $(-3.9 \mathrm{~cm})$ with a corresponding increase in lean body mass $(+1.1 \mathrm{~kg})$ in the high dairy group, whereas no significant changes were observed in the low dairy group. The reduction in body fat in the high dairy group was also accompanied by a significant increase in circulating glycerol, suggesting an increase in lipolysis in these subjects. In the second trial, 29 obese African-American adults were randomized to the low and high dairy diets that were calorie-restricted (-500 kcal/d) for $24 \mathrm{wk}$. Although both diets resulted in significant weight and fat loss, the high dairy diet caused about a 2 -fold greater reduction in weight $(-11$ $\mathrm{kg})$ and fat loss $(-9.1 \mathrm{~kg})$ compared with the low calcium/ low dairy diet ( -5.9 and $-4.0 \mathrm{~kg}$, respectively), and loss of lean body mass was markedly less $(-0.1 \mathrm{~kg})$ compared with the low dairy diet $(-1.99 \mathrm{~kg})$.

Taken together, these data add to a growing body of clinical and epidemiological reports that support the notion that dietary calcium and dairy foods may act to help control excess adiposity. Furthermore, the clinical observation of increased plasma glycerol is consistent with previous findings of an antilipolytic effect of 1,25dihydroxyvitamin D in human adipocytes and a corres- ponding increase in lipolysis in animals fed high-calcium and high-dairy food diets.

Mechanisms of Action for Calcium/Dairy Foods' Role in Weight Management. In a model of human obesity, transgenic obese mice overexpressing the agouti gene specifically in adipocytes demonstrated a beneficial effect of calcium, and particularly dairy foods, on body weight and body fat. Obese mice fed a highfat/high-sucrose diet low in calcium for 6 wk exhibited marked increases in adipocyte lipogenesis (fat formation), decreases in lipolysis, and increases in body weight and body fat mass. However, high-calcium diets reduced lipogenesis and stimulated lipolysis, resulting in reductions in body weight gain and body fat. Dairy food sources of calcium (nonfat dry milk) had significantly greater effects than calcium alone. When obese mice were fed an energy-restricted diet, dietary calcium and, to a greater extent, calcium from nonfat dry milk increased lipolysis, decreased lipogenesis, and accelerated loss of body weight and fat.

In vitro studies in cultured human adipocytes and in the agouti obese mouse model provide a plausible mechanism whereby calcium/dairy food intake modulates energy metabolism and obesity risk. Low calcium diets have been shown to increase the calcium-regulating hormones, 1,25-dihydroxyvitamin $\mathrm{D}$ and parathyroid hormone, which in turn increase intracellular calcium concentrations in human adipocytes. Intracellular calcium plays an important role in regulating both lipogenesis and lipolysis in human adipocytes. Increased intracellular calcium stimulates lipogenic gene expression and fatty acid synthase, a key enzyme in de novo lipogenesis. Intracellular calcium also inhibits lipolysis, resulting in increased fat storage. Conversely, a high calcium intake has been shown to inhibit production of 1,25-dihydroxyvitamin $\mathrm{D}$ thereby decreasing intracellular calcium, which in turn decreased fatty acid synthase activity, increased plasma glycerol, and ultimately decreased the fat content of adipocytes.

An increase in body core temperature observed in obese mice fed high-calcium diets implied calcium's ability to alter energy metabolism from storage to expenditure whereas no increase in caloric expenditure was observed in obese rats fed a similar high-calcium diet. Recent data suggest that calcium also increases thermogenesis in humans. In a retrospective analysis of previous calcium intake studies, using whole-body, indirect calorimetry, it was shown that high calcium intake is positively related with whole-body fat oxidation over a 24 -h period.

Another mechanism whereby dietary calcium intake may reduce body adiposity is by inhibiting fat absorption from the gastrointestinal tract and increasing fecal loss of fatty acids and energy through the formation 
and excretion of calcium-fatty acid soaps. Although this mechanism would appear insufficient to fully explain the greater weight and fat losses found in the human studies of high calcium and high dairy food diets, data from a short-term study examining the effects of a highcalcium diet $(1,800 \mathrm{mg} / \mathrm{d})$ provided mainly from low-fat dairy products had no effect on 24-h energy expenditure or fat oxidation, but fecal fat excretion increased 2.5fold and fecal energy excretion was significantly increased (1,045 vs. $684 \mathrm{~kJ} / \mathrm{d})$ compared with a low calcium diet $(400 \mathrm{mg} / \mathrm{d})$.

Taken together, rapidly emerging evidence from animal model studies, observational data, and a growing number of clinical interventions, are supportive of a significant inverse relationship between the intake of dairy foods and augmented reductions in body fat in obese animals and humans under conditions of caloric deficit.

\section{CANCER}

Diet is one of several environmental factors actively being investigated for its role in cancer. An estimated one-third of all cancers may be related to what we eat. Research indicates that some nutrients or food components, when consumed in excess, may promote cancer (e.g., alcohol, fat, and calories), whereas others may be protective against this disease, including many that are found naturally in dairy foods.

Calcium and Vitamin D. It has been more than $25 \mathrm{yr}$ since Garland and Garland at Johns Hopkins University first proposed that calcium and vitamin D may reduce the risk of colon cancer. Since then, many, but not all, case-control and prospective epidemiological studies as well as clinical intervention studies have supported this hypothesis. Calcium and vitamin D intake have been shown to be inversely associated with colon cancer incidence and mortality in epidemiological studies performed in the United States and other countries. Humans obtain vitamin D through synthesis in the body from exposure to sunlight and from vitamin D-fortified foods such as milk.

Numerous case-control and prospective epidemiological studies have observed a protective association for calcium and vitamin D on colon cancer. In a 1997 casecontrol study, Slattery and colleagues reported an inverse association between the intake of dietary calcium (>800 mg/d) from milk and other dairy products and the risk of colon cancer especially in males and, to a lesser degree, in females. Since that time, other small and large case-control studies involving subjects in the United States, Sweden, Canada, and Australia have observed a protective effect of higher calcium intakes against colon cancer. In a large case-control study in
Los Angeles County, California, an inverse association was observed between increased intake of dietary calcium and vitamin $\mathrm{D}$ and a reduced risk of colon cancer. Additionally, when specific foods were examined, a protective effect against colon cancer was observed for yogurt that was independent of its calcium content, suggesting that components in yogurt besides calcium may be protective. However, no inverse association was observed between increased dietary calcium intake from fermented or unfermented dairy products and colon cancer risk in a case-control study from the Netherlands.

Clinical studies also support a protective role for calcium or dairy foods against colon cancer. In a randomized, single-blind, controlled study of 70 patients with a history of developing polyps or noncancerous growths in the colon, Holt and coworkers at St. Luke's/Roosevelt Hospital (New York, NY) showed that increasing the intake of calcium from about 600 to $1,500 \mathrm{mg} / \mathrm{d}$ from food sources, specifically dairy foods such as low-fat milk, reduced the risk for colon cancer. At 6 and 12 mo, positive changes were observed, including a reduction in colonic epithelial cell proliferation and a restoration of normal cell differentiation-associated properties. In a follow-up study that compared the effects of calcium supplements $(900 \mathrm{mg} / \mathrm{d})$ with an equal amount of calcium from low-fat dairy foods in 40 adults at risk for colon cancer, Holt and coworkers reported that both supplemental calcium and dairy foods reduced epithelial cell proliferation indexes from a high to a lower risk pattern. In a randomized case-control study of 930 adults with a recent history of colorectal adenomas, Baron and coworkers at Dartmouth Medical School found that increasing calcium intake by $1,200 \mathrm{mg} / \mathrm{d}$ from calcium carbonate reduced the incidence of recurrent adenomatous polyps by $19 \%$ and the total number of tumors by $24 \%$ in less than $1 \mathrm{yr}$.

Many, but not all, prospective epidemiological studies of large groups of individuals over time have supported a beneficial effect of dietary calcium and vitamin $\mathrm{D}$ on reducing colon cancer risk.

$\mathrm{Wu}$ and colleagues at the Harvard School of Public Health reported results from 2 large-scale prospective studies in the United States: the Nurses' Health Study involving nearly 88,000 women, and the Health Professionals Follow-Up Study involving more than 47,000 men showing that higher calcium intake was associated with a significant reduction in the risk of distal colon cancer but not proximal colon cancer. Specifically, compared with subjects with low calcium intake $(\leq 500 \mathrm{mg} /$ d), those with intakes $>700 \mathrm{mg} / \mathrm{d}$ from food sources (e.g., dairy foods) or from calcium supplements had a significantly lower risk of distal colon cancer. In the United States, about two-thirds of all colon cancer cases occur 
in the distal colon. These authors concluded that: "Considering the public health importance of colon cancer, even a modest protective effect of higher calcium intake on colon cancer could result in the prevention of a large number of colon cancer cases". In a follow-up study by Cho and coworkers, an examination of the associations between the consumption of dairy foods and calcium and colorectal cancer risk in a pooled analysis of 10 of the largest prospective epidemiological studies from North America and Europe found that increased consumption of milk and calcium were related to a lower risk of colorectal cancer. They concluded that the data, in combination with previous studies documenting a beneficial effect of calcium supplementation on colonic epithelial cell turnover and colorectal adenoma recurrence, support the concept that moderate milk and calcium intake reduces the risk of colorectal cancer.

In further analysis of data from observational studies and randomized controlled trials, McCarron and Heaney from the University of California-Davis and Creighton University estimated that consuming 3 to 4 servings of dairy foods per day may reduce the risk of colorectal cancer by $5 \%$ annually after $3 \mathrm{yr}$, resulting in healthcare cost savings of $\$ 1$ billion over $5 \mathrm{yr}$.

Conjugated Linoleic Acid. Conjugated linoleic acid (CLA) is a collective term used to describe one or more of the $\mathrm{C} 18$ dienoic positional and geometric fatty acid isomers of the essential fatty acid, linoleic acid (18:2, $\mathrm{n}-6)$. In 1979, Pariza and coworkers at the University of Wisconsin discovered that a substance extracted from cooked beef inhibited mutagenesis. They later reported that the "substance" consisted of a mixture of C18 conjugated diene cis and trans geometric isomers of linoleic acid, which they termed conjugated linoleic acid. Dairy products and ruminant meats contribute the primary source of naturally occurring CLA in the human diet. Dairy products account for approximately $75 \%$ of the estimated 100 to $300 \mathrm{mg}$ of CLA consumed per day. Milk fat contains numerous cis, trans, and trans,cis isomers of CLA at positions $\Delta 7,9 ; \Delta 8,10 ; \Delta 9,11 ; \Delta 10,12$; $\Delta 11,13$; and $\Delta 12,14$ of the 18 -carbon fatty acid chain and these account for approximately $0.7 \%$ of milk fat. The cis-9,trans-11 CLA isomer, however, is the predominant CLA isomer accounting for about 75 to $90 \%$ of the total CLA in milk fat, whereas the major isomers in synthetic preparations of CLA from vegetable oil sources are mixtures of cis-9, trans-11 and trans-10,cis12 isomers. Although CLA is produced as a biohydrogenation intermediate in the rumen, studies by Bauman and colleagues have reported that endogenous synthesis of CLA in the mammary gland accounts for the majority of the cis-9,trans-11 CLA present in milk fat with about 70 to over $90 \%$ derived from the conversion of vaccenic acid (18:1,trans-11), a rumen biohydrogena- tion intermediate, by $\Delta^{9}$-desaturase. Based on clinical studies indicating that humans can also convert vaccenic acid to CLA, it has been suggested that the dietary intake of CLA should be multiplied by 1.4 to attain a more accurate estimate of the "effective CLA" derived from ruminant meat and dairy products.

Unlike linoleic acid, which has been shown to stimulate carcinogenesis in animal models, CLA has been shown to protect against carcinogenesis in vitro in a wide range of human cancer cell lines and in vivo in a number of animal models of chemically induced skin papillomas, forestomach neoplasias, and preneoplastic lesions and tumors of the colon and mammary gland. The consistency of the data set on the anticarcingenic properties of CLA prompted a National Academy of Sciences report on natural anticarcinogens to point out that: "CLA is the only fatty acid shown unequivocally to inhibit carcinogenesis in experimental animals" (National Research Council, 1996). Additionally, research findings suggest that CLA may have other potential health benefits including inhibition and regression of atherosclerosis, changes in body fat metabolism and partitioning, antidiabetic effects, and enhancement of bone growth.

The anticarcinogenic activities of CLA are noteworthy based on studies conducted by Ip and coworkers at the Roswell Park Cancer Institute (Buffalo, NY) using a chemically induced rat model of mammary carcinogenesis. Importantly, these studies demonstrated that the inhibitory effect of a mixed isomer preparation of CLA (i.e., 1:1 cis-9,trans-11 and trans-10,cis-12 plus low levels of other isomers) on mammary carcinogenesis resulted in a dose-dependent reduction in the incidence and number of tumors with dietary levels as low as $0.05 \%(\mathrm{wt} / \mathrm{wt})$ and maximally effective at $1 \%$. Furthermore, the effects of CLA are independent of the type and level of fat in the diet and are observed when fed as either a free fatty acid or triglyceride. Other studies have demonstrated that both isomers of CLA (i.e., cis9,trans-11 CLA and trans-10,cis-12 CLA) appear to be equally effective in inhibiting tumors in the rat mammary gland. These researchers also demonstrated that feeding CLA to rats early in life (prepubertal period) provided protection against tumor development later in life after administration of the carcinogen. On the other hand, if CLA feeding was withheld until after mature development of the mammary gland, the optimal anticarcinogenic effects were observed only when CLA was fed continuously after administration of the carcinogen. These data, along with the observation that CLA is preferentially incorporated into mammary adipocyte triglycerides, suggested that mammary adipocyte triglycerides might act as a local reservoir for CLA that can provide anticarcinogenic effects later in life. 
Importantly, unlike a number of species in which dietary trans-10,cis-12 CLA can reduce body fat depots, CLA does not have an effect on the size or lipid levels of rat fat pads, thus indicating that CLA feeding results not only in a percentage increase in mammary gland lipid CLA but also in an absolute increase in CLA levels in the rat mammary gland.

The biological mechanism by which CLA exerts its anticarcinogenic effects in mammary tissue is an active area of research, and the reader is referred to an excellent review by Ip and colleagues for a more thorough coverage of potential mechanisms. Briefly, studies indicate that CLA may inhibit mammary carcinogenesis by targeting normal or initiated epithelial cells within the anatomical structures of the mammary epithelium including ducts, alveoli, and terminal end buds, or in transformed epithelial cells resulting in an inhibition of cell growth, alterations in differentiation, or induction of cell death. Conjugated linoleic acids may influence these effects directly by delivery through the blood, or indirectly from mammary adipocytes by conversion of vaccenic acid to CLA and release of CLA to the surrounding mammary epithelial tissue.

In general, most studies on the anticarcinogenic effects of CLA have been conducted using synthetic preparations of CLA from vegetable oil sources consisting of a mixture of cis-9,trans-11 and trans-10,cis-12 isomers. Recently, researchers from Roswell Park Cancer Institute in collaboration with Cornell University have evaluated the effects of butterfat naturally enhanced in CLA on the inhibition of rat mammary carcinogenesis. In dairy cows fed a standard commercial diet supplemented with vegetable and fish oils, cis-9, trans-11 CLA content was enhanced 7-fold over control butter (3.76 vs. $0.51 \mathrm{~g} / 100 \mathrm{~g}$ of fatty acids) and constituted over $90 \%$ of the total CLA isomers. Additionally, the precursor of CLA, vaccenic acid (VA), was increased over 12-fold (16.28 vs. $1.3 \mathrm{~g} / 100 \mathrm{~g}$ of fatty acids). Results of initial studies demonstrated that the CLA-enriched butterfat effectively inhibited rat mammary carcinogenesis in a dose-dependent manner and was just as effective as synthetic cis-9,trans-11 CLA. Unexpectedly, more CLA accumulated in the mammary fat pad of rats fed the CLA-enriched butter than in rats fed synthetic cis9 ,trans-11 suggesting, as discussed previously, that the VA present in the butterfat might be converted endogenously to CLA, thus providing an additive anticarcinogenic effect. In subsequent studies, it was established that VA is anticarcinogenic and resulted in a dose-dependent increase in mammary fat CLA and a parallel decrease in mammary tumorigenesis whether VA was supplied in a synthetic form or naturally from VA- and CLA-enriched butterfat. Furthermore, feeding studies using inhibitors of $\Delta^{9}$-desaturase demonstrated that the anticarcinogenic effect of VA and the corresponding increase in tissue levels of CLA could be markedly attenuated. Thus, these data show that the anticarcinogenic effects of VA are predominantly mediated through its conversion to cis-9,trans-11 CLA via $\Delta^{9}$-desaturase. Taken together, these animal model studies strongly indicate that CLA is a promising candidate as a dietary component for the prevention of some cancers, especially breast cancer.

Although the amount of cis-9,trans-11 CLA necessary to provide a protective effect in humans is not known, extrapolations based on body weight from the effective doses of CLA used to reduce chemically induced tumors in rats, as well as considerations of metabolic rate differences between rodents and humans has prompted some researchers to estimate that 700 to $800 \mathrm{mg} / \mathrm{d}$ of CLA may be required for humans. Based on the estimated intake of CLA, which ranges from 100 to 300 $\mathrm{mg} / \mathrm{d}$, and the conversion rate of VA to CLA in humans (estimated to be about 20\%), it has been suggested that the CLA intake from ruminant foods should be multiplied by 1.4 to more closely estimate the "effective" CLA intake. Using this approach, the actual "effective" CLA intake may be closer to 140 to $420 \mathrm{mg} / \mathrm{d}$. Although this amount is still 2 to 5 times lower than the estimated intake that may provide protective effects, it is clear that these levels could be achieved with dairy products containing CLA- and VA-enhanced milk fat.

\section{CONCLUSIONS}

Milk and dairy foods are the major source of calcium in the US diet, providing over $70 \%$ of the calcium available in the food supply. In addition, dairy foods provide substantial amounts of other essential nutrients including potassium, phosphorus, riboflavin, vitamin $\mathrm{B}_{12}$, protein, zinc, magnesium, and vitamin A. Evidence from clinical and epidemiological studies published since 1975 indicates that consuming adequate amounts of calcium or calcium-rich foods such as milk and other dairy foods throughout life helps to optimize peak bone mass development by age 30 or earlier, slow age-related bone loss, and reduce the risk of osteoporotic fracture in later adult years. This point is reinforced in the new 2005 Dietary Guidelines for Americans and in the 2004 Surgeon General's Report on Bone Health and Osteoporosis, which recommends 3 servings of milk products per day, and suggests that milk product consumption may have additional health attributes beyond bone health.

A considerable database of observational and clinical trials exists regarding the beneficial effects of dairy food consumption on blood pressure and the reduced risk of hypertension. Prospective and cross-sectional observa- 
tional studies indicate that dairy food consumption is associated with lower prevalence as well as lower risk of developing hypertension. The results of randomized controlled clinical trials suggest that the consumption of recommended levels of dairy products can contribute to lower systolic and diastolic blood pressure in individuals with normal and elevated blood pressure. The blood pressure-lowering effect of dairy foods is best exemplified by the DASH clinical trial. This study demonstrated that a low-fat dietary pattern containing lowfat dairy products ( $\sim 3$ servings/d) and high in fruits and vegetables ( 8 to 9 servings/d) produced greater reductions in systolic and diastolic blood pressure than either a diet high in only fruits and vegetables or the control diet (a typical American diet).

Recent reports from animal, epidemiological, and clinical studies have provided strong support for a beneficial effect of increased dairy foods on body weight and fat loss. Animal studies have demonstrated an important role of increased dairy on decreasing body weight and body fat during over consumption and during energy restriction. Most observational data and clinical trial results indicate a statistically significant inverse relationship between dairy intake/calcium intake and body weight and body fat loss. Recent clinical studies have also demonstrated that body weight and body fat loss occurs when adequate calcium is provided by supplements and that this effect is augmented further by an equivalent amount of calcium supplied from dairy foods, indicating that additional nutrients from dairy foods are playing a role.

Several case-control and prospective epidemiological studies and one intervention study support a beneficial role for calcium against colon cancer. In individuals at risk for colon cancer, hyperproliferation of colon epithelium is reduced toward normal by increased dietary calcium. In a pooled analysis of 10 prospective epidemiological studies, it was found that increased consumption of milk and calcium were associated with a lower risk of colorectal cancer. Based on the evidence to date, consumption of recommended intakes for calcium and vitamin $\mathrm{D}$, especially from dairy foods that are major sources of these nutrients in the US diet, appears to be a prudent measure to reduce the risk of colon cancer. Conjugated linoleic acid and vaccenic acids are fatty acids found naturally in dairy products and ruminant meats that may confer anticarcinogenic and antiatherogenic benefits. Although the protective effects of CLA on breast cancer are compelling, human applications must be approached with extreme caution until human data are accumulated on safety and efficacy. Human prevention trials of breast cancer present substantial challenges due to the chronic nature of breast cancer as an end point and the prohibitive costs of these studies.
Rather, there is a critical need to determine intermediate biomarkers of CLA efficacy that effectively predict cancer outcomes and could be tested in women at high risk for breast cancer.

\section{REFERENCES}

Apple, L. J., T. H. Moore, E. Obarzanek, W. Vollmen, L. P. Svetky, F. M. Sacks, G. M. Bray, T. M. Vogt, J. A. Cutler, M. M. Windhauser, P. H. Lin, and N. Karanja. 1997. For the DASH Collaborative Research Group: A clinical trial of the effects of dietary patterns on blood pressure. N. Engl. J. Med. 336:1117-1124.

Arbman, G., O. Axelson, A.-B. Ericsson-Begodzki, M. Fredriksson, E. Nilsson, and R. Sjodhal. 1992. Cereal fiber, calcium, and colorectal cancer. Cancer 69:2042-2048.

Birkett, N. J. 1998. Comments on a meta-analysis on the relationship between dietary calcium intake and blood pressure. Am. J. Epidemiol. 148:223-228.

Bucher, H. C., R. J. Cook, G. H. Guyatt, J. D. Lang, D. J. Cook, R. Hatala, and D. L. Hunt. 1996. Effects of dietary calcium supplementation on blood pressure: A meta-analysis of randomized controlled trials. JAMA 275:1016-1022.

Cho, E., S. A. Smith-Warner, D. Spiegelman, W. L. Beeson, P. A. van der Brandt, G. A. Colditz, A. R. Folsom, G. E. Fraser, J. L. Fruendenheim, E. Giovannucci, R. A. Goldbohm, S. Graham, A. B. Miller, P. Pietinen, J. D. Potter, T. E. Rohan, P. Toniolo, M. J. Virtanen, W. C. Willett, A. Wolk, K. Wu, S. S. Yaun, A. ZeleniuchJacquotte, and D. A. Hunter. 2004. Dairy foods, calcium, and colorectal cancer: A pooled analysis of 10 cohort studies. J. Natl. Cancer Inst. 96:1015-1022.

Devine, A., R. L. Prince, and R. Bell. 1996. Nutritional effect of calcium supplementation by skim milk powder or calcium tablets on total nutrient intake in postmenopausal women. Am. J. Clin. Nutr. 64:731-737.

FitzGerald, R. J., B. A. Murray, and D. J. Walsh. 2004. Hypotensive peptides from milk proteins. J. Nutr. 134:980S-988S.

Food and Nutrition Board. 1989. Commission on Life Sciences, NRC, Recommended Dietary Allowances. 10th ed. Natl. Acad. Press, Washington, DC.

Food and Nutrition Board. 1997. Institute of Medicine, Standing Committee on the Scientific Evaluation of Dietary Reference Intakes. Dietary Reference Intakes for Calcium, Phosphorus, Magnesium, Vitamin D, and Fluoride. Natl. Acad. Press, Washington, DC.

Frommer, D., M. Buchanan, A. Woodger, and E. Kalafatos. 1993. Can raised feacal calcium concentration protect against colorectal neoplasms? Gastrointest. Oncol. 104: (4, part 2) (Abstr.)

Fulgoni, V. L., P. J. Huth, D. B. DiRienzo, and G. D. Miller. 2004. Determination of the optimal number of dairy servings to ensure a low prevalence of inadequate calcium intake in Americans. J. Am. Coll. Nutr. 23:651-659.

Garland, C. F., and F. C. Garland. 1980. Do sunlight and vitamin D reduce the risk of colon cancer? Int. J. Epidemiol. 9:227-231.

Gerrior, S., and L. Bente. 2002. Nutrient content of the US food supply, 1909-1999: A summary report. USDA Center for Nutrition Policy and Promotion, Washington, DC.

Ghadirian, P., A. Lacroix, P. Maisonneuve, C. Perret, C. Potvin, D. Gravel, D. Bernard, and P. Boyle. 1997. Nutritional factors and colon carcinoma: A case-control study involving French Canadians in Montreal, Quebec, Canada. Cancer 80:858-864.

Glinghammar, B., M. Venturi, I. R. Rowland, and J. J. Rafter. 1997. Shift from a dairy product-rich to a dairy product-free diet: Influence on cytotoxicity and genotoxicity of fecal water-potential risk factors for colon cancer. Am. J. Clin. Nutr. 66:1277-1282.

Griffith, L. E., G. H. Guyatt, R. J. Cook, H. C. Bucher, and D. J. Cook. 1999. The influence of dietary and nondietary calcium supplement on blood pressure: An updated meta-analysis of randomized controlled trials. Am. J. Hypertens. 12:84-92.

Heaney, R. P. 2000. Calcium, dairy products and osteoporosis. J. Am. Coll. Nutr. 19:83S-99S. 
Heaney, R. P. 2002. The importance of calcium intake for lifelong skeletal health. Calcif. Tissue Int. 70:70-73.

Heaney R. P., S. Abrams, B. Dawson-Hughes, A. Looker, R. Marcus, V. Matkovic, and C. Weaver. 2000. Peak bone mass. Osteoporosis Int. 11:985-1009.

Heaney, R. P., K. M. Davies, and J. Barger-Lutz. 2002. Calcium and weight: Clinical studies. J. Am. Coll. Nutr. 21:152S-155S.

Holt, P. R., E. O. Atillasoy, J. Gilman, J. Guss, S. F. Moss, H. Newmark, K. Fan, K. Yang, and M. Lipkin. 1998. Modulation of abnormal colonic epithelial cell proliferation and differentiation by lowfat dairy foods. JAMA 280:1074-1079.

Holt, P. R., C. Wolper, S. F. Moss, K. Tang, and M. Lipkin. 2001. Comparison of calcium supplementation or low-fat dairy foods on epithelial cell proliferation and differentiation. Nutr. Cancer 41:150-155.

Hu, J. F., X. H. Zhao, J. B. Jia, B. Parpia, and T. C. Campbell. 1993. Dietary calcium and bone density among middle-aged elderly women in China. Am. J. Clin. Nutr. 58:219-227.

Ip, M. M., P. A. Masso-Welch, and C. Ip. 2003. Prevention of mammary cancer with conjugated linoleic acid: Role of the stroma and the epithelium. J. Mammary Gland Biol. Neoplasia 8:103-118.

Jacobsen, R., J. K. Lorenzen, S. Toubro, I. Krog-Mikkelsen, and A. Astrup. 2005. Effect of short-term high dietary calcium intake on 24-h energy expenditure, fat oxidation, and fecal fat excretion. Int. J. Obes. Relat. Metab. Disord. 29:292-301.

Jacqmain, M., E. Doucet, J.-P. Despres, C. Bouchard, and A. Tremblay. 2003. Calcium intake, body composition, and lipoproteinlipid concentration in adults. Am. J. Clin. Nutr. 77:1448-1452.

Kampman, E., P. Vantveer, G. J. Hiddink, P. Van Aken-Schneijder, F. J. Kok, and R. J. Hermus. 1994. Fermented dairy products, dietary calcium and colon cancer: A case-control study in the Netherlands. Int. J. Cancer 59:170-176.

Matkovic, V., and R. P. Heaney. 1992. Calcium balance during human growth. Evidence for threshold behavior. Am. J. Clin. Nutr. 55:992-996.

Matkovic, V., K. Kostial, I. Simonovic, R. Buzina, A. Brodarec, and B. E. C. Nordin. 1979. Bone status and fracture rates in two regions of Yugoslavia. Am. J. Clin. Nutr. 32:540-549.

McCarron, D. A., and R. P. Heaney. 2004. Estimated healthcare savings associated with adequate dairy food intake. Am. J. Hypertens. 17:88-97.

McCarron, D. A., C. D. Morris, H. J. Henry, and J. L. Stanton. 1984. Blood pressure and nutrient intake in the United States. Science 224:1392-1398.

Melanson, E. L., T. A. Sharp, J. Schneider, W. T. Donahoo, G. K. Grunwald, and J. O. Hill. 2003. Relation between calcium intake and fat oxidation in adult humans. Int. J. Obes. 27:196-203.

Miller, G. D., J. K. Jarvis, and L. D. McBean. 2000. Pages 155-191 in Handbook of Dairy Foods and Nutrition. 2nd ed. CRC Press, Boca Raton, FL.

New, S. A., C. Bolton-Smith, D. A. Grubb, and D. M. Reiz. 1997. Nutritional influences on bone mineral density: A cross-sectional study in premenopausal women. Am. J. Clin. Nutr. 65:1831-1839.

Newton-John, H. F., and B. D. Morgan. 1970. The loss of bone with age: Osteoporosis and fractures. Clin. Orthop. 71:229-232.

Pereira, M. A., D. R. Jacobs, L. Van Horn, M. L. Slattery, A. I. Katashov, and D. S. Ludwig. 2002. Dairy consumption, obesity, and the insulin resistance syndrome in young adults: The CARDIA study. JAMA 287:2081-2089.

Papakonstantinou, E., W. P. Flatt, P. J. Huth, and R. B. S. Harris. 2003. High dietary calcium reduces body fat content, digestibility of fat, and serum vitamin D in rats. Obes. Res. 11:387-394.

Peters, R. K., M. C. Pike, D. Garabrant, and T. M. Mack. 1992. Diet and colon cancer in Los Angeles County, California. Cancer Causes Control 3:457-473.
Putnam, J. 2000. Major trends in US food supply, 1909-99. Food Rev. 23:8-15.

Sacks, F. M., L. P. Svetkey, W. M. Vollmer, L. J. Appel, G. A. Bray, D. Harsha, E. Obarzanek, P. R. Conlin, E. R. Miller, III, D. G. Simons-Morton, N. Karanja, and P. H. Lin. 2001. For the DASHSodium Collaborative Research Group. A clinical trial of the effects on blood pressure of reduced dietary sodium and the DASH dietary pattern (the DASH-Sodium Trial). N. Engl. J. Med. 344:3-10.

Shamik, J. P., and J. A. Yanovsky. 2003. Calcium intake and adiposity. Am. J. Clin. Nutr. 77:281-287.

Shi, H., D. DiRienzo, and M. B. Zemel. 2001. Effects of dietary calcium on adipocyte lipid metabolism and body weight regulation in energy-restricted aP2-agouti transgenic mice. FASEB J. 15:291293.

Slattery, M. L., B. J. Caan, J. D. Potter, T. D. Berry, A. Coates, D. Duncan, and S. L. Edwards. 1997. Dietary energy sources and colon cancer risk. Am. J. Epidemiol. 145:199-210.

Sorensen, A. W., M. L. Slattery, and M. H. Ford. 1988. Dietary calcium and colon cancer: Review. Nutr. Cancer 11:135-145.

Sun, X., and M. B. Zemel. 2004. Calcium and dairy products inhibit weight and fat regain during ad libitum consumption following energy restriction in ap2-agouti transgenic mice. J. Nutr. 134:3054-3060.

Svetkey, L. P., D. Simons-Morton, W. M. Vollemer, L. J. Appel, P. R. Conlin, D. H. Ryan, J. Ard, and B. M. Kennedy. 1999. Effects of dietary patterns on blood pressure. Subgroup analysis of the Dietary Approaches to Stop Hypertension (DASH) randomized clinical trial. Arch. Intern. Med. 159:285-293.

Tylavsky, F. A. 2004. Nutritional influences on bone growth in children. J. Nutr. 134:689S-690S.

United States Department of Agriculture. 2005. Dietary Guidelines for Americans. U.S. Department of Health and Human Services. Available at: www.healthierus.gov/dietaryguidelines

United States Department of Health and Human Services. 2004. Bone Health and Osteoporosis: A Report of the Surgeon General. Office of the Surgeon General, US Department of Health and Human Services, Rockville, MD.

Weaver, C. M. 2001. Calcium. Page 276 in Present knowledge in nutrition. 8th ed. ILSI Press, International Life Sciences Institute, Washington, DC.

Welten, D. C., H. C. G. Kemper, G. B. Post, and W. A. Van Staveren. 1995. A meta-analysis of the effect of calcium intake on bone mass in young and middle aged females and males. J. Nutr. 125:2802-2813.

Writing Group of the PREMIER Collaborative Research Group. 2003. Effects of comprehensive lifestyle modification on blood pressure control. Main results of the PREMIER clinical trial. JAMA 289:2083-2093.

Wu, K., C. Willet, S. Fuschs, G. A. Colditz, and E. L. Giovannuci. 2002. Calcium intake and risk of colon cancer in women and men. J. Natl. Cancer Inst. 94:437-444.

Zemel, M. B., J. Richards, S. Mathis, A. Milstead, L. Gebhardt, and E. Silva. 2005. Dairy augmentation of total and central fat loss in obese subjects. Int. J. Obes. Relat. Metab. Disord. 29:391-397.

Zemel, M. B., J. Richards, A. Milstead, and P. Campbell. 2005. Effects of calcium and dairy on body composition and weight loss in African-American adults. Obes. Res. 13:1218-1225.

Zemel, M. B., H. Shi, B. Geer, D. B. DiRienzo, and P. C. Zemel. 2000. Regulation of adiposity by dietary calcium. FASEB J. 14:11321138.

Zemel, M. B., W. Thompson, A. Milstead, K. Morris, and P. Campbell. 2004. Calcium and dairy acceleration of weight and fat loss during energy restriction in obese adults. Obes. Res. 12:582-590. 